\title{
A Study on Mathematical Modeling of CDC Damper and Its Characteristics Test
}

\author{
Xiaohui Bai ${ }^{1,2, a}$, Yon Huang ${ }^{1,2}$, Wenji Tang ${ }^{3, b}$, Junhao Yang ${ }^{3, c}$, Zhaohong Liu $^{3}$ \\ ${ }^{1}$ Transportation and Automotive Engineering Institute, Xihua University, Chengdu, 610000, China \\ ${ }^{2}$ Automobile Engineering Key Laboratory of Sichuan Province \\ ${ }^{3}$ Chengdu Konghui Automobile Science \& Technology Co Ltd \\ aemail:baixh@khat.cc, ${ }^{b}$ email:tangwj@khat.cc, ${ }^{c}$ email:yangjh@khat.cc
}

Keywords: CDC Damper; Simulation; Solenoid Valve

\begin{abstract}
The full name of CDC is Continuous Damping Control, CDC damper is an important part of the Semi-active suspension system, and its damping force is controlled by a solenoid valve. We put the CDC damper as the research object, according to its structure and working principle to establish the corresponding mathematical model of hydraulic pressure. CDC damper characteristics curve is obtained by simulation, and compared with the experimental data. Results show that the experimental curve and the simulation curves are basically identical, so simulation model can provide the theoretical reference for design and characteristics analysis of the CDC damper.
\end{abstract}

\section{Introduction}

Compared with traditional damper, CDC damper used in Semi-active suspension system can significantly increase the ride and the handling [3]. As an important part of the semi-active suspension control system, design and research of CDC damper is very important. In domestic, the study of the CDC damper more concentrated on the aspect of control algorithm, and the theoretical study of the structure is less.

The working principle of CDC damper and traditional damper is similar, just add a controllable CDC solenoid valve [1]. We can start by controlling the duty cycle of the PWM wave to change the solenoid valve current, then change the orifice throttling area, realize the continuous control of damping force. The larger current is, the smaller damping force will be.

\section{Structure and Working principle of CDC damper}

The structure and working principle of CDC damper as shown in Figure.1, it is consist of compression chamber, rebound chamber, oil storage chamber, middle chamber, piston rod, piston valve system, bottom valve system and solenoid valve assembly, etc. Piston valve system and bottom valve system is check valve as valve plates - throttling mouth type. Solenoid valve assembly is consist of flood valve, check valve and current control valve which controlled by the PWM wave.

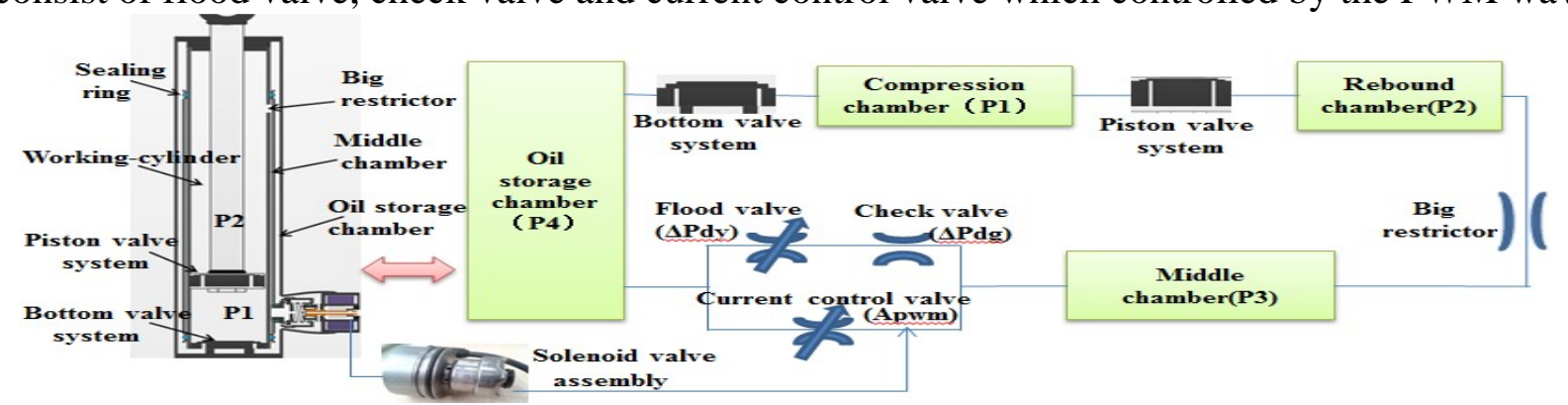

Figure.1 structure and working principle of CDC damper

During the compression stroke, check valve (between the bottom valve system and the oil storage chamber) is closed, Oil pressure of the compression chamber is on a rise, piston valve system is opened, the oil flow from the compression chamber into the rebound chamber. Excess oil 
flow (because the piston rod into the working-cylinder) from big restrictor (between middle chamber and rebound chamber) into the middle chamber, then flow from CDC solenoid valve assembly back to the oil storage chamber.

During the rebound stroke, bottom valve system is opened, piston valve system is closed, oil flow from oil storage chamber into compression chamber. The oil of rebound chamber flow form big restrictor into middle chamber, then flow form CDC solenoid valve assembly into oil storage chamber.

From the above analysis, we can know that whether rebound stroke or compression stroke, the oil always goes through the CDC solenoid valve assembly and one-way flow. So, we can start by controlling the PWM duty cycle to change the solenoid valve current, then change the orifice throttling area, realize the continuous control of damping force.

\section{Mathematical model of CDC damper}

To build a completely accurate CDC damper mathematical model is very complex and difficult. In order to establish mathematical model for enough precision, we make these hypothesizes [4]: 1, CDC damper has no leakage of liquid and gas in the process of work. 2, oil temperature change does not affect the CDC damper characteristics. 3, ignore the gravitational potential energy caused by oil flow and the influence of gravity of piston rod. 4, ignore the friction between the piston and working-cylinder. 5, the oil bulk modulus is constant. 6 , the change in pressure had no effect on the deformation of damper components. According to the structure and working principle of CDC damper, establish the corresponding mathematical model of hydraulic pressure, as shown in figure1. Set the average pressure of compression chamber, rebound chamber ,middle chamber, oil storage chamber respectively is: $P 1, P 2, P 3, P 4$. The pressure difference on both sides of check valve, flood valve respectively is: $\Delta P d g, \Delta P d y$. Flood valve opening pressure is $\Delta P y 0$, oil density is $\rho$. Sectional area of piston and piston rod respectively is: $A h, A g$. Ddy is the diameter of the flood valve orifice .Atmospheric pressure is Pair, Ce is flow coefficient of orifice, Apwm is the opening area of orifice controlled by current. Speed of the piston upward movement is $V$, as the positive direction.

In the oil storage chamber, gas compression and expansion can be nearly considered as adiabatic process. According to the principle of force balance, we can think that the pressure of the liquid is equals to the pressure of the gas. At the same time, as the big restrictor is much bigger, so the resistance of the throttle can be ignored, the oil pressure of the middle chamber and rebound chamber is equal, then:

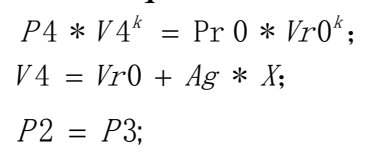

In the formula, the pressure and volume of gas changes (before and after) respectively is: $\mathrm{Pr} 0$, VrO, P4, V4. $X$ is vertical displacement of the CDC damper.

According to the structure of the CDC solenoid valve assembly, the throttle orifice controlled by PWM wave is composed of six same size round holes, the larger current is, the smaller damping force will be. The area of the fixed orifice of check valve is Adg, it is consist of 10 rectangular holes. Flood valve opening area is related to its edge pressure difference on both ends. Under the action of pressure difference, the deflection of flood valve opening is Hdy, then:

$$
\begin{aligned}
& A d g=\sum \operatorname{Adgi}, \quad(\mathrm{i}=1 \cdots 10) \\
& H d y=G d y *(\Delta \mathrm{Pdy}-\Delta \mathrm{Py} 0) / \mathrm{h}^{3} \\
& \Delta P d g+\Delta P d y=P 3-P 4
\end{aligned}
$$

In the formula, $h$ is Valve plate thickness. $G d y$ is bending deformation coefficient of valve plate. The CDC solenoid valve has two kinds of working mode, with electricity or no electricity. Piston moves up and down, causing the volume changes of oil in compression and rebound chamber, $\mathrm{V}>0$ 
is the rebound stroke and $\mathrm{V}<0$ is the compression stroke. When the viscous fluid flow through the throttle, according to the relationship between the flow rate and pressure difference, we can find[6]:

1. Current control valve working with power.

$$
\begin{aligned}
& \left.\begin{array}{l}
A g * V ; \quad(\mathrm{V}<0) \\
(A H-A g) * \mathrm{~V} ;(\mathrm{V}>0)
\end{array}\right\}=C e * A p w m * \sqrt{2 *(\mathrm{p} 3-\mathrm{p} 4) / \rho}, \Delta p d y \leq \Delta p y 0 \\
& \left.\begin{array}{l}
A g * V ; \quad(\mathrm{V}<0) \\
(A H-A g) * \mathrm{~V} ;(\mathrm{V}>0)
\end{array}\right\}=\text { Ce* Apwm* } \sqrt{2 *(p 3-p 4) / \rho}+C e * \pi * D d y * \mathrm{H} d y * \sqrt{2 * \Delta p d y / \rho}, \Delta p d y>\Delta p y 0 \\
& A h * V= \begin{cases}C e * \text { Ahy } * \sqrt{2 *(\mathrm{p} 1-\mathrm{p} 2) / \rho} & (\mathrm{V}<0) \\
C e * \text { Adf } * \sqrt{2 *(\mathrm{p} 4-\mathrm{p} 1) / \rho} & (\mathrm{V}>0)\end{cases}
\end{aligned}
$$

Simultaneous equation(1)-(9),CDC damper force is:

Fopen $=\left\{\begin{array}{l}\text { Fopeny }=p 1 * A h-p 2 *(\mathrm{Ah}-\mathrm{Ag})-\text { Pair } * \mathrm{Ag} \quad(\mathrm{V}<0) \\ \text { Fopenf }=-p 1 * A h+p 2 *(\mathrm{Ah}-\mathrm{Ag})+\text { Pair } * \mathrm{Ag} \quad(\mathrm{V}>0)\end{array}\right.$

2. Current control valve working without power, the oil pressure is large enough and oil only flow from check valve and flood valve back to the oil storage chamber:

$$
\begin{aligned}
& \left.A g * V ; \quad \begin{array}{l}
\mathrm{V}<0) \\
(A h-A g) * \mathrm{~V} ;(\mathrm{V}>0)
\end{array}\right\}=\mathrm{Ce} * \mathrm{Adg} * \sqrt{2 * \Delta P d g / \rho}=C e * \pi * D d y * H d y * \sqrt{2 * \Delta P d y / \rho} \\
& A h * V= \begin{cases}\mathrm{Ce} * \text { Ahy } * \sqrt{2 *(\mathrm{P} 1-\mathrm{P} 2) / \rho} & (\mathrm{V}<0) \\
\mathrm{Ce} * \text { Ahy } * \sqrt{2 *(\mathrm{P} 4-\mathrm{P} 1) / \rho} & (\mathrm{V}>0)\end{cases}
\end{aligned}
$$

Simultaneous above equation, CDC damper force is:

Fclose $=\left\{\begin{array}{l}\text { Fclosey }=p 1 * A h-p 2 *(\mathrm{Ah}-\mathrm{Ag})-\text { Pair } * \mathrm{Ag} \quad(\mathrm{V}<0) \\ \text { Fclosef }=-p 1 * A h+p 2 *(\mathrm{Ah}-\mathrm{Ag})+\text { Pair } * \mathrm{Ag} \quad(\mathrm{V}>0)\end{array}\right.$

\section{Contrast of Simulation and experiment}

According to Chinese damper test standard QC/T545 [2], we adopt sine excitation method for

\begin{tabular}{|c|c|c|c|c|c|c|c|c|c|c|c|c|c|c|c|c|c|c|c|c|c|}
\hline \multirow{2}{*}{$1 / A \underbrace{\mathrm{FF} / \mathrm{m}^{*} \mathrm{~s}^{-1}}_{(\max )}$} & \multicolumn{2}{|l|}{0.05} & \multicolumn{2}{|c|}{0.129} & \multicolumn{2}{|c|}{0.258} & \multicolumn{2}{|c|}{0.385} & \multicolumn{2}{|l|}{0.52} & \multirow{2}{*}{$\begin{array}{l}\mathrm{V} / \mathrm{m}^{*} \mathrm{~s}^{-1} \\
\mathrm{~F} / \mathrm{s} / \mathrm{M} \\
(\mathrm{min})\end{array}$} & \multicolumn{2}{|c|}{0.05} & \multicolumn{2}{|c|}{0.129} & \multicolumn{2}{|c|}{0.258} & \multicolumn{2}{|c|}{0.385} & \multicolumn{2}{|l|}{0.52} \\
\hline & test & simulation & test & simulation & test & simulation & test & simulation & test & simulation & & test & simulation & test & simulation & test & simulation & test & simulation & test & simulation \\
\hline o & 789 & 801 & 1760 & 1756 & 2175 & 2177 & 2391 & 2403 & 2601 & 2571 & 0 & .317 & .320 & .602 & -617 & -858 & -870 & -965 & -972 & -1065 & -1106 \\
\hline 0.22 & 766 & 770 & 1755 & 1740 & 2162 & 2101 & 2384 & 2394 & 2591 & 2544 & 0.22 & .322 & .324 & .632 & -638 & -857 & -868 & -962 & -966 & -1075 & -1104 \\
\hline 0.40 & 758 & 751 & 1718 & 1719 & 2150 & 2081 & 2330 & 2294 & 2501 & 2461 & 0.40 & .315 & .321 & -610 & -611 & .855 & .863 & -966 & -974 & -1070 & -1092 \\
\hline 0.65 & 398 & 412 & 1314 & 1366 & 1792 & 1799 & 2062 & 2040 & 2244 & 2211 & 0.65 & -258 & -260 & -439 & -444 & -744 & -749 & -884 & -892 & -993 & -1007 \\
\hline 0.85 & 241 & 235 & 915 & 1001 & 1361 & 1230 & 1620 & 1625 & 1873 & 1870 & 0.85 & .237 & .238 & .376 & .379 & .639 & .666 & .807 & .809 & .922 & -933 \\
\hline 1.0 & 200 & 201 & 757 & 806 & 1122 & 1066 & 1339 & 1340 & 1557 & 1553 & 1.0 & -231 & -230 & -354 & -355 & -591 & -597 & .753 & .754 & -866 & -879 \\
\hline 1.23 & 165 & 163 & 640 & 637 & 956 & 966 & 1141 & 1136 & 1328 & 1299 & 1.23 & .229 & -228 & .333 & -335 & -553 & -564 & .708 & -711 & -819 & -830 \\
\hline 1.42 & 148 & 152 & 512 & 490 & 769 & 789 & 930 & 927 & 1081 & 1072 & 1.42 & -227 & -226 & .323 & .321 & .505 & .504 & -642 & -647 & .746 & .759 \\
\hline 1.60 & 134 & 144 & 424 & 435 & 645 & 663 & 789 & 773 & 923 & 924 & 1.60 & -226 & .226 & -315 & -317 & -475 & -473 & -600 & -599 & -695 & -701 \\
\hline
\end{tabular}
CDC damper, and experiment system is shown in figure .2. The relationship between the speed and frequency of vertical movement of damper piston is as follows:

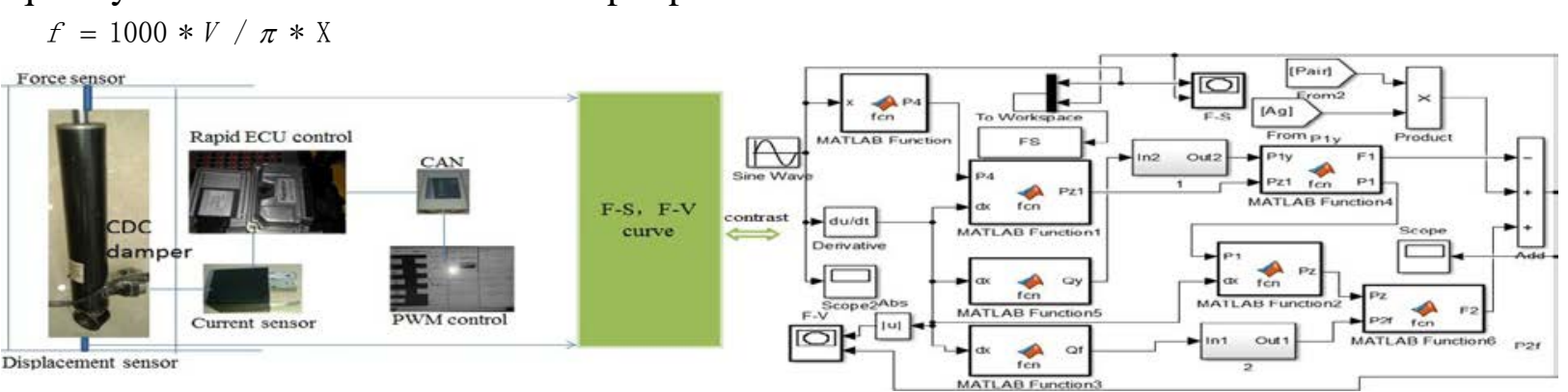

Figure.2 CDC damper characteristics test and simulation model

Figure.3 contrast of simulation and experiment (Fmax and Fmin)

We can control the current of CDC solenoid valve by controlling the duty cycle of PWM wave, and get the CDC damper's F - S curve and F - V curves under different opening of orifice. According to the experiment data to calculate the effective work current of this CDC damper, its effective working current is range from 0.3A to 1.5A.Through the matlab/simulink simulation, change size of Apwm, make it match to the different current size. Under different current and speed, contrast of simulation data and experimental data is shown in figure 3. 

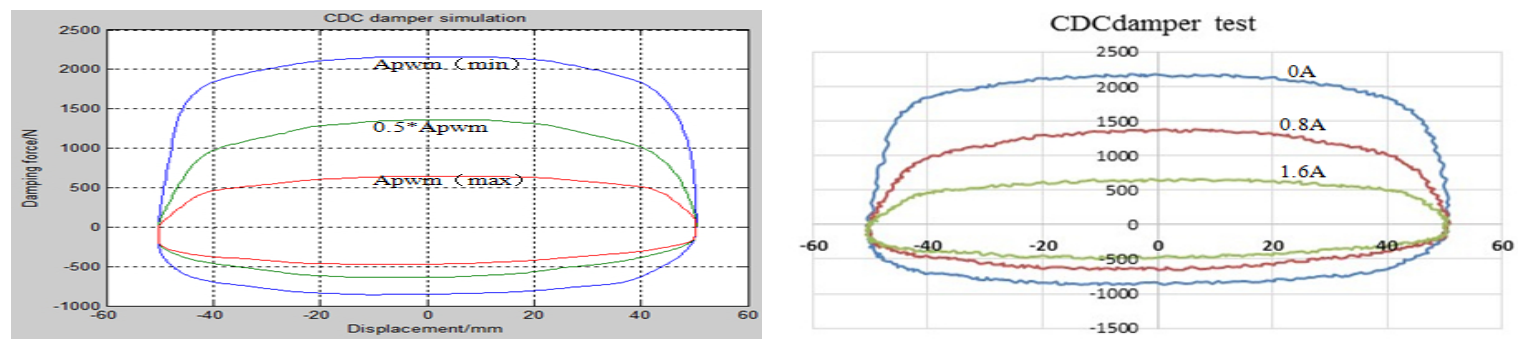

Figure.4 contrast of simulation and experiment (F - S)
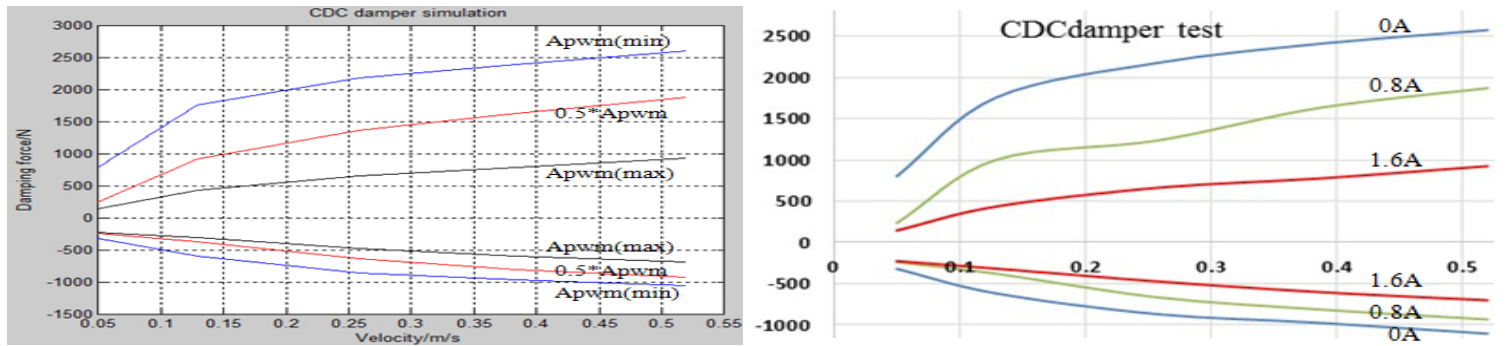

Figure.5 contrast of simulation and experiment (F-V)

By comparing the simulation curves with experimental curves of CDC damper(F-S,F-V), as shown in firure.4 and figure.5, in three kinds of working conditions (CDC damper current respectively is: $0 A, 0.8 A, 1.6 A$. and solenoid valve throttle mouth area of simulation model respectively is: Apwm ( $\left.\min ), 0.5^{*} A p w m, A p w m(\max )\right)$, we can find that the simulation curves and the experimental curves are basically identical, the error of data within the scope of control.

\section{Summary}

According to the structure and the working principle of CDC damper, establish the corresponding mathematical model of hydraulic pressure. Compared the simulation curve with the experimental data, we can find that the simulation model is effective. This simulation model can provide the theoretical reference for design and characteristics analysis of the CDC damper.

\section{References}

[1] John C. Dixon. Shock Absorber Handbook[M]. Mechanical industry press.2011,10.

[2] QC/T545-1999 Automobile shock absorber bench experiment method[S].1999.

[3] Kitching K J,Cole D J, Cebon D. Characteristics of a Semi-Active Damper for Heavy Vehicles[J].Transaction of the ASME,2000,122(9):498-506.

[4] Se Kyung Oh, Yong Hwan Yoon. A Study on the performance of Variable Valve for Reverse Continuous Damper[J].International Journal of Mechanical, Aerospace, Industrial and Mechatronics Engineering Vol:1 No:8,2007

[5] Guang Xia, Wuwei Chen, Xiwen Tang. Simulation and Experimental Study on Novel Solenoid-actuated Shock Absorber[J].Automotive Engineering. 2012(Vol.34) No.11.

[6] Changcheng Zhou. Design and Characteristics Simulation of Automobile Damper [M].Mechanical industry press.2012,5. 